Research Paper

\title{
Comparison of Short-Term Outcomes between Button-Type Bipolar Plasma Vaporization and Transurethral Resection for the Prostate: A Systematic Review and Meta-Analysis
}

\author{
Xiaonan Zheng ${ }^{1^{*}}$, Xin $\mathrm{Han}^{2^{*}}$, Dehong Cao ${ }^{1^{*}}$, Yaping Wang ${ }^{2}$, Hang $\mathrm{Xu}^{2}$, Lu Yang${ }^{1}$, Qiang Wei ${ }^{1 凶}$, Jianzhong Ai ${ }^{\bowtie}$ \\ 1. Department of Urology, Institute of Urology, West China Hospital, Sichuan University, Chengdu, Sichuan. P.R. China; \\ 2. West China Medical School, Sichuan University, Chengdu, Sichuan. P.R. China. \\ *These authors have contributed equally to this work \\ $\triangle$ Corresponding authors: Jianzhong Ai, Email: Jianzhong.Ai@scu.edu.cn and Qiang Wei, Tel: +86 18980601425, Fax: +86 2885422451, E-mail: \\ weiqiang163163@163.com; No. 37, Guoxue Road, Chengdu, Sichuan, P.R. China; Post Code: 610041
}

() The author(s). This is an open access article distributed under the terms of the Creative Commons Attribution License (https://creativecommons.org/licenses/by/4.0/). See http://ivyspring.com/terms for full terms and conditions.

Received: 2019.07.22; Accepted: 2019.10.01; Published: 2019.10.21

\begin{abstract}
Background: Previous meta-analysis evaluated a limited number of parameters regarding the comparison of BTPV and TURP for BPH.

Method: PubMed, Embase and Cochrane Library were searched for literature comparing BTPV with TURP. Data of efficacy (IPSS, Qmax, PVR and QoL) and safety were extracted and evaluated using either SMD or OR with $95 \% \mathrm{Cl}$. All analyses were performed by RevMan 5.3 .

Results: Eleven trials with 1690 patients were selected. Compare to BTPV, TURP had better 6-month IPSS $(\mathrm{SMD}=0.36,95 \% \mathrm{Cl} 0.08$ to 0.63$)$, better $1-(\mathrm{SMD}=-0.38,95 \% \mathrm{Cl}-0.63$ to -0.12$), 6-(\mathrm{SMD}=-0.73,95 \% \mathrm{Cl}-0.99$ to -0.46) and 12-month Qmax (SMD=-0.47, 95\% Cl -0.85 to -0.10$)$, better 6-month PVR (SMD=1.18, 95\% Cl 0.87 to 1.48 ), as well as better $3-(S M D=-0.24,95 \% \mathrm{Cl}-0.48$ to -0.01 ) and 6-month QoL (SMD $=-0.62,95 \% \mathrm{Cl}$ -0.91 to -0.33 ). However, BTPV had shorter catheterization time (SMD $=-0.96,95 \% \mathrm{Cl}-1.12$ to -0.79 ) and hospital stay (SMD $=-0.71,95 \% \mathrm{Cl}-0.89$ to -0.53 ), less hemoglobin decrease (SMD $=-1.09,95 \% \mathrm{Cl}-1.27$ to -0.91 ) and virtually shorter operation time $(S M D=-0.15,95 \% \mathrm{Cl}-0.31$ to 0.01$)$. Moreover, BTPV had fewer occurrence of overall complications $(\mathrm{OR}=0.52,95 \% \mathrm{Cl} 0.40$ to 0.69$)$, Clavien III-IV complications (OR=0.61, $95 \% \mathrm{Cl} 0.37$ to 1.02 ), blood transfusion ( $\mathrm{OR}=0.25,95 \% \mathrm{Cl} 0.09$ to 0.69 ), hematuria (OR=0.27, $95 \% \mathrm{Cl} 0.13$ to 0.56 ) and capsular perforation ( $O R=0.19,95 \% \mathrm{Cl} 0.08$ to 0.48$)$. Subgroup analysis indicated BTPV and bipolar TURP had similar total complications (OR 1.08, 95\% Cl 0.40-2.88, P=0.88) and Clavien III-IV complications (OR $1.42,95 \% \mathrm{Cl} 0.36-5.57, \mathrm{P}=0.61$ ) and blood transfusion rate (OR $0.28,95 \% \mathrm{Cl} 0.04-1.73, \mathrm{P}=0.17$ ).

Conclusion: Both TURP and BTPV could significantly improve IPPS, Qmax, PVR and QoL. TURP had slightly better short-term efficacy, while BTPV had better safety. However, subgroup analysis found bipolar TURP and BTPV had similar safety.
\end{abstract}

Key words: lower urinary tract symptoms (LUTS), benign prostatic hyperplasia (BPH), button-type bipolar plasma vaporization (BTPV), transurethral resection (TURP)

\section{Introduction}

Lower urinary tract symptoms (LUTS) are commonly observed in elderly males [1]. It has been believed that LUTS is related to bladder outlet obstruction caused by benign prostatic hyperplasia (BPH) $[2,3]$. Transurethral resection of the prostate (TURP), a surgery which removes tissues from the transition region, is the standard treatment for $\mathrm{BPH}$ for decades and strongly recommended by the latest European Association of Urology (EAU) guideline for treating a prostate volume ranging from 30 to $80 \mathrm{~mL}$ [4]. While the efficacy of TURP to improve International Prostate Symptom Score (IPSS), 
maximum flow rate (Qmax), postvoiding residual (PVR), and quality of life (QoL) remains promising, complications still emerge after TURP [5-7]. As a common alternative to TURP, bipolar transurethral vaporization of the prostate (BTPV) creates a constant plasma field, vaporize a limited layer of prostate tissue and produce a TURP-like cavity [8]. One advantage BTPV has over TURP is the presence of a coagulation area above the vaporized zone, which subsequently mitigates bleeding and other complications [9]. The most recent and frequently evaluated BTPV system has been the "button-type" BTPV, which has a "mushroom-like" electrode. The past meta-analysis on BTPV and TURP only included a limited set of parameters on efficacy and safety[10]. This study aims to update and expand the pooled evidence regarding "button-type" BTPV and provide a more comprehensive clinical guidance.

\section{Methods}

\section{Study selection}

Studies from PubMed, Embase, and Cochrane Library were systematically identified using keywords ("benign prostatic hyperplasia") AND ("vaporization" OR "transurethral resection") published until March 2019. Inclusion criteria were as follows: (1) Trials comparing BTPV and TURP for $\mathrm{BPH}$; (2) those that provide comparison data regarding efficacy or safety; and (3) those published in English.

References cited in this paper from other studies were also cross reviewed for potential inclusion. In cases of where two datasets were duplicated, only one study pertain the dataset would be included. When the overlap was partial, all studies would be included in whole. When results were reported by the same series of studies, the most recent and most complete data with the longest follow-up duration would be included.

\section{Data extraction and analysis}

This meta-analysis was conducted in accordance with the Preferred Reporting Items for Systematic Reviews and Meta-Analyses guidelines. The most important outcomes compared were those related to the efficacy of BTPV and TURP, which included IPSS, Qmax, QoL, and PVR. Apart from efficacy, tolerability and safety (complications, operative time, hemoglobin decrease, catheterization time, and hospitalization time) were also compared. Subgroup analyses were performed by comparing BTPV with only monopolar or only bipolar TURP. This study utilized Review Manager (version 5.3) to calculate standard mean differences (SMD) together with 95\% confidence intervals (CIs) for continuous variables and estimate odds ratios (ORs) for dichotomous variables. Inter-study heterogeneity was tested using $I^{2}$ test, with an $I^{2}>50 \%$ denoting heterogeneity. Two authors (Xiaonan Zheng and Hang $\mathrm{Xu}$ ) extracted the data independently, and all the authors resolved discrepancies by consensus.

\section{Results}

\section{Study characteristics}

A total of 1586 articles were identified, among which 62 underwent a full-text review and 11 were ultimately selected (Figure 1) [11-21]. Among the selected studies, nine were chosen as randomized controlled trials, one as a prospective nonrandomized study, and one as a retrospective study. The mean follow-up duration ranged from 3 months to 18 months. A total of 1690 patients with a mean age ranging from 56.3 to 73.9 years were selected, among whom 940 underwent TURP and 750 underwent BTPV. The baseline prostate volume, IPSS, Qmax, QoL, and PVR are presented in Table 1.

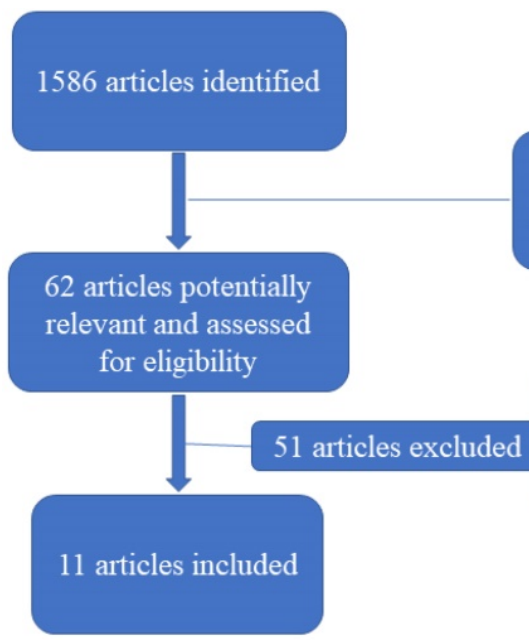

1524 articles excluded

based on title and abstract

62 articles potentially

relevant and assessed

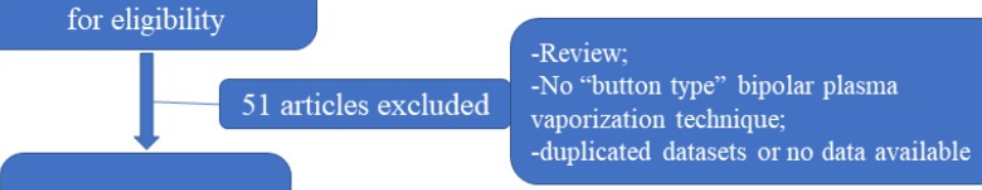

11 articles included 
Table 1. Characteristics of included studies.

\begin{tabular}{|c|c|c|c|c|c|c|c|c|c|c|c|c|}
\hline Study & Design & Equipment & $\begin{array}{l}\text { Cohort } \\
\text { Size }\end{array}$ & TURP & BTPV & $\begin{array}{l}\text { Age } \\
\text { (year) }\end{array}$ & $\begin{array}{l}\text { Follow-Up } \\
\text { (month) }\end{array}$ & $\begin{array}{l}\text { Prostate } \\
\text { Volume } \\
(\mathrm{ml})\end{array}$ & IPSS & $\begin{array}{l}\text { Qmax } \\
(\mathrm{mL} / \mathrm{s})\end{array}$ & QoL & $\begin{array}{l}\text { PVR } \\
(\mathrm{ml})\end{array}$ \\
\hline $\begin{array}{l}\text { Geavlete } \\
2010^{*}\end{array}$ & $\begin{array}{l}\text { Randomized } \\
\text { Controlled }\end{array}$ & $\begin{array}{l}\text { Standard monopolar (26-F Storz } \\
\text { resectoscope) and BTPV (Olympus } \\
\text { SurgMaster UES-40) }\end{array}$ & 155 & 80 & 75 & 66 & 6 & 55.99 & 24.3 & 6.3 & 4.3 & 85.1 \\
\hline $\begin{array}{l}\text { Geavlete } \\
2011\end{array}$ & $\begin{array}{l}\text { Randomized } \\
\text { Controlled }\end{array}$ & $\begin{array}{l}\text { Standard monopolar (26-F Storz } \\
\text { resectoscope) and BTVP (Olympus } \\
\text { SurgMaster UES-40) }\end{array}$ & 510 & 340 & 170 & 67 & 18 & 54.2 & 24.2 & 6.4 & 4.4 & 91.7 \\
\hline $\begin{array}{l}\text { Geavlete } \\
2013\end{array}$ & $\begin{array}{l}\text { Randomized } \\
\text { Controlled }\end{array}$ & $\begin{array}{l}\text { Standard monopolar (26-F Storz } \\
\text { resectoscope) and BTPV (Olympus Surg } \\
\text { Master UES-40 and Olympus ESG-400; } \\
\text { Olympus Winter \& iBE GMBH, } \\
\text { Kuehnstraße, Hamburg, Germany) }\end{array}$ & 180 & 60 & 120 & 68.8 & 6 & 51.7 & 24 & 6.6 & 4.1 & 104.7 \\
\hline $\begin{array}{l}\text { Nuhoglu } \\
2011\end{array}$ & $\begin{array}{l}\text { Randomized } \\
\text { Controlled }\end{array}$ & $\begin{array}{l}\text { Standard monopolar (26-F Storz } \\
\text { resectoscope) and BTPV (Olympus } \\
\text { SurgMaster UES-40) }\end{array}$ & 90 & 47 & 43 & 65.03 & 12 & 52.42 & 21.1 & 5.4 & $\mathrm{~N}$ & 96.4 \\
\hline Yip 2011 & $\begin{array}{l}\text { Randomized } \\
\text { Controlled }\end{array}$ & $\begin{array}{l}\text { Standard bipolar (Olympus SurgMaster) } \\
\text { and BTPV (Olympus SurgMaster UES-40) }\end{array}$ & 86 & 40 & 46 & 69.27 & 12 & 61.2 & 22.3 & 7.9 & $\mathrm{~N}$ & $\mathrm{~N}$ \\
\hline Zhang 2012 & $\begin{array}{l}\text { Randomized } \\
\text { Controlled }\end{array}$ & $\begin{array}{l}\text { Standard monopolar (26-F resectoscope) and } \\
\text { BTPV (Olympus SurgMaster UES-40) }\end{array}$ & 30 & 15 & 15 & 70.6 & 6 & 64.55 & 25.8 & 4.9 & 5.1 & $\mathrm{~N}$ \\
\hline $\begin{array}{l}\text { Falahatkar } \\
2014\end{array}$ & $\begin{array}{l}\text { Randomized } \\
\text { Controlled }\end{array}$ & $\begin{array}{l}\text { Standard bipolar and BTPV (Olympus } \\
\text { SurgMaster UES-40) }\end{array}$ & 88 & 49 & 39 & 73.9 & 3 & 47.04 & 26.2 & 8.3 & $\mathrm{~N}$ & $\mathrm{~N}$ \\
\hline $\begin{array}{l}\text { Aboutaleb } \\
2015\end{array}$ & Retrospective & $\begin{array}{l}\text { Standard monopolar (24-F Storz } \\
\text { resectoscope) and BTPV (Olympus } \\
\text { SurgMaster UES-40) }\end{array}$ & 152 & 100 & 52 & 64.2 & 3 & 44 & 20.3 & 4.3 & 11.5 & 170 \\
\hline $\begin{array}{l}\text { Geavlete } \\
2015\end{array}$ & $\begin{array}{l}\text { Randomized } \\
\text { Controlled }\end{array}$ & $\begin{array}{l}\text { Standard bipolar (26F OES-Pro resectoscope) } \\
\text { and BTPV (Olympus SurgMaster UES-40) }\end{array}$ & 160 & 80 & 80 & 68.5 & 12 & 124.3 & 24.8 & 6.7 & 4.4 & 154.9 \\
\hline $\begin{array}{l}\text { Elsakka } \\
2016\end{array}$ & $\begin{array}{l}\text { Randomized } \\
\text { Controlled }\end{array}$ & $\begin{array}{l}\text { Standard monopolar (26-F resectoscope) and } \\
\text { BTPV (Olympus SurgMaster UES-40) }\end{array}$ & 82 & 40 & 42 & 56.3 & 6 & 48.32 & 24.25 & 6.91 & $\mathrm{~N}$ & 208.71 \\
\hline $\begin{array}{l}\text { Kranzbühler } \\
2017\end{array}$ & $\begin{array}{l}\text { Prospective } \\
\text { Non- } \\
\text { randomized }\end{array}$ & $\begin{array}{l}\text { Standard monopolar (26-F Wolf } \\
\text { resectoscope) and BTPV (Olympus } \\
\text { SurgMaster UES-40) }\end{array}$ & 157 & 89 & 68 & 65.4 & 12 & 44.6 & 17.7 & 9.6 & 4.6 & 74.6 \\
\hline
\end{tabular}

${ }^{*}$ Geavlete 2010 is included in Geavlete 2011; N = Data not applicable.

\section{Efficacy}

According to six trials with 588 patients, postoperative IPSS was significantly improved in both groups (Figure 2), although no significant differences were observed in 1-month (SMD -0.04, 95\% CI -0.30 to $0.21 ; \mathrm{P}=0.73$ ), 3-month (SMD $0.06,95 \% \mathrm{CI}-0.12$ to $0.24 ; \mathrm{P}=0.51$ ) and 12-month (SMD 0.06, 95\% CI -0.19 to $0.32 ; \mathrm{P}=0.64)$ IPSS. However, the TURP group had better 6-month IPSS (SMD 0.36, 95\% CI 0.08 to 0.63; P $=0.01$ ) than the BTPV group.

Six trials showed that both groups had significantly improved postoperative Qmax (Figure 2), although the TURP group had better 1-month (SMD -0.38, 95\% CI -0.63 to -0.12 ; $\mathrm{P}=0.004$ ), 6-month Qmax (SMD -0.73, 95\% CI -0.99 to -0.46; P < 0.00001 ) and $\geq 12$-month (SMD $-0.47,95 \% \mathrm{CI}-0.85$ to $-0.10, P=0.01$ ) Qmax than the BTPV group. However, no significant difference in postoperative 3-month Qmax had been observed (SMD 0.11, 95\% CI -0.07 to $0.29 ; \mathrm{P}=0.23$ ).

Four trials analyzing PVR (Figure 3) showed that postoperative values were significantly lower than preoperative values in both groups. Moreover, the TURP group had a higher 3-month PVR, albeit not so significant (SMD 0.14, 95\% CI -0.08 to $0.36 ; \mathrm{P}=0.21$ ), and a significantly lower 6-month PVR (SMD 1.18,
$95 \%$ CI 0.87 to $1.48 ; \mathrm{P}<0.00001)$ compared to the BTPV group. In spite of those, both groups had similar 12-month PVR after treatment (SMD -0.04, $95 \%$ CI -0.29 to 0.22 ).

Three studies investigating postoperative QoL (Figure 4) showed that patients in both groups had significantly better QoL after treatment. But it is worth noting that TURP group yields a better result than BTPV group in both 3-month (SMD -0.24, 95\% CI -0.48 to -0.01 ) and 6-month (SMD $-0.62,95 \%$ CI -0.91 to -0.33 ) QoL.

\section{Safety and tolerability}

Figure 4 compares the occurrence of complications between both groups. Respectively, the BTPV group had significantly fewer total complications (OR 0.52, 95\% CI 0.40 to 0.69 ; P < 0.00001 ), lesser need for blood transfusion (OR 0.25, $95 \%$ CI 0.09 to $0.69 ; \mathrm{P}=0.005$ ), fewer hematuria (OR $0.27,95 \%$ CI 0.13 to $0.56 ; \mathrm{P}=0.0004)$, fewer capsular perforations (OR $0.19,95 \% \mathrm{CI} 0.08$ to $0.48 ; \mathrm{P}=0.0005$ ), and significantly fewer Clavien 3-4 complications (OR $0.61,95 \%$ CI 0.37 to 1.02 ) compared to the TURP group.

However, no significant differences in postoperative urethral stricture (OR 0.76, 95\% CI 0.41 to $1.38 ; \mathrm{P}=0.36$ ), urinary incontinence (OR $0.36,95 \%$ 
CI 0.08 to $1.66 ; \mathrm{P}=0.19)$, urinary retention (OR 1.11, $95 \% \mathrm{CI} 0.51$ to $2.41 ; \mathrm{P}=0.80$ ), TUR syndrome (OR 0.33, $95 \%$ CI 0.06 to $1.94 ; \mathrm{P}=0.22)$, urinary tract infection (OR 1.95, 95\% CI 0.96 to $4.00 ; \mathrm{P}=0.07$ ), clot retention (OR 0.38, 95\% CI 0.11 to $1.29 ; \mathrm{P}=0.12$ ), dysuria (OR
$1.21,95 \% \mathrm{CI} 0.79$ to $1.87 ; \mathrm{P}=0.38$ ), re-catheterization (OR 0.79, 95\% CI 0.46 to $1.38 ; \mathrm{P}=0.41$ ), and retreatment (OR $0.63,95 \% \mathrm{CI} 0.32$ to $1.23, \mathrm{P}=0.18$ ) were observed between both groups.

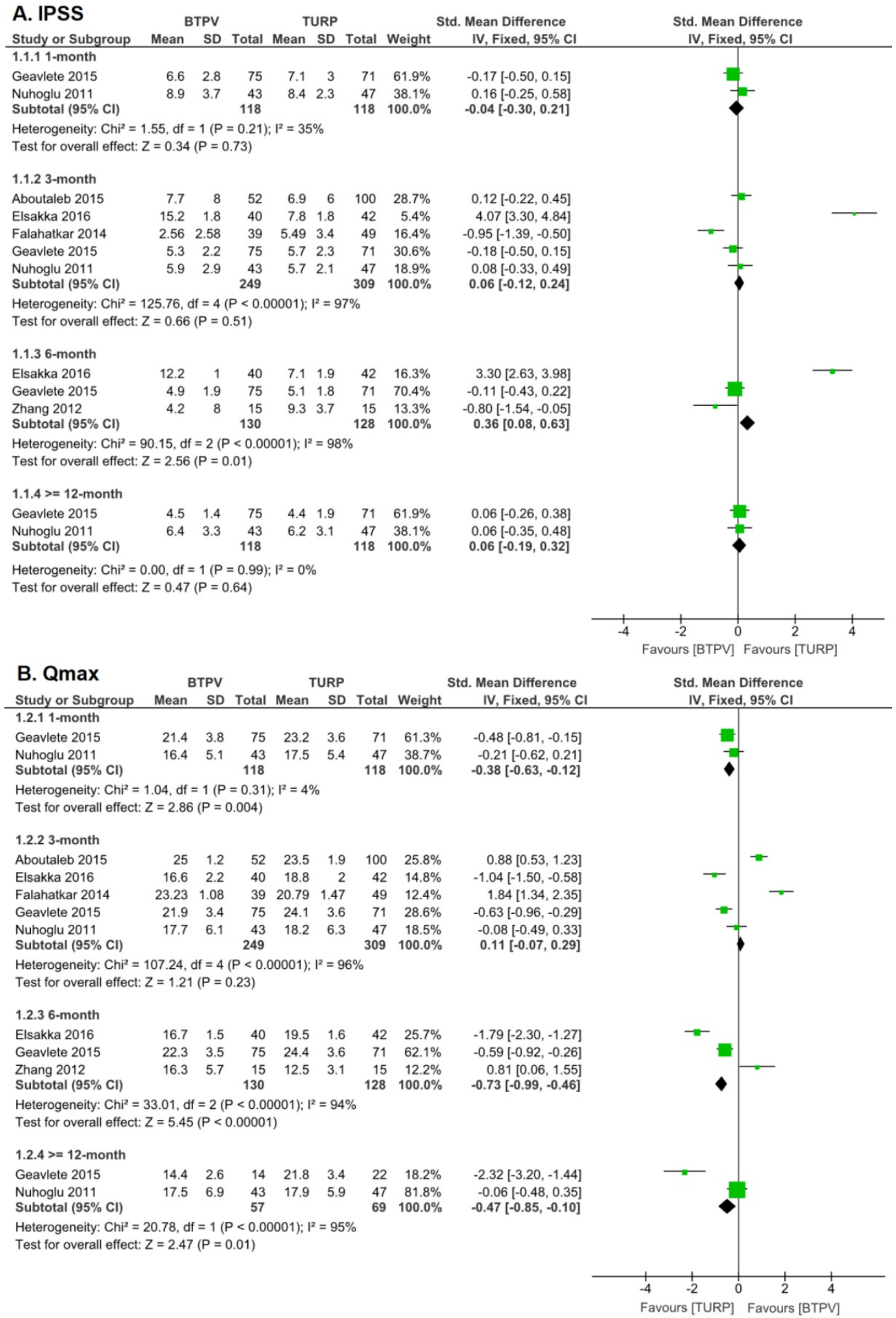

Figure 2. IPSS and Qmax after treatment. A. IPSS; B. Qmax 


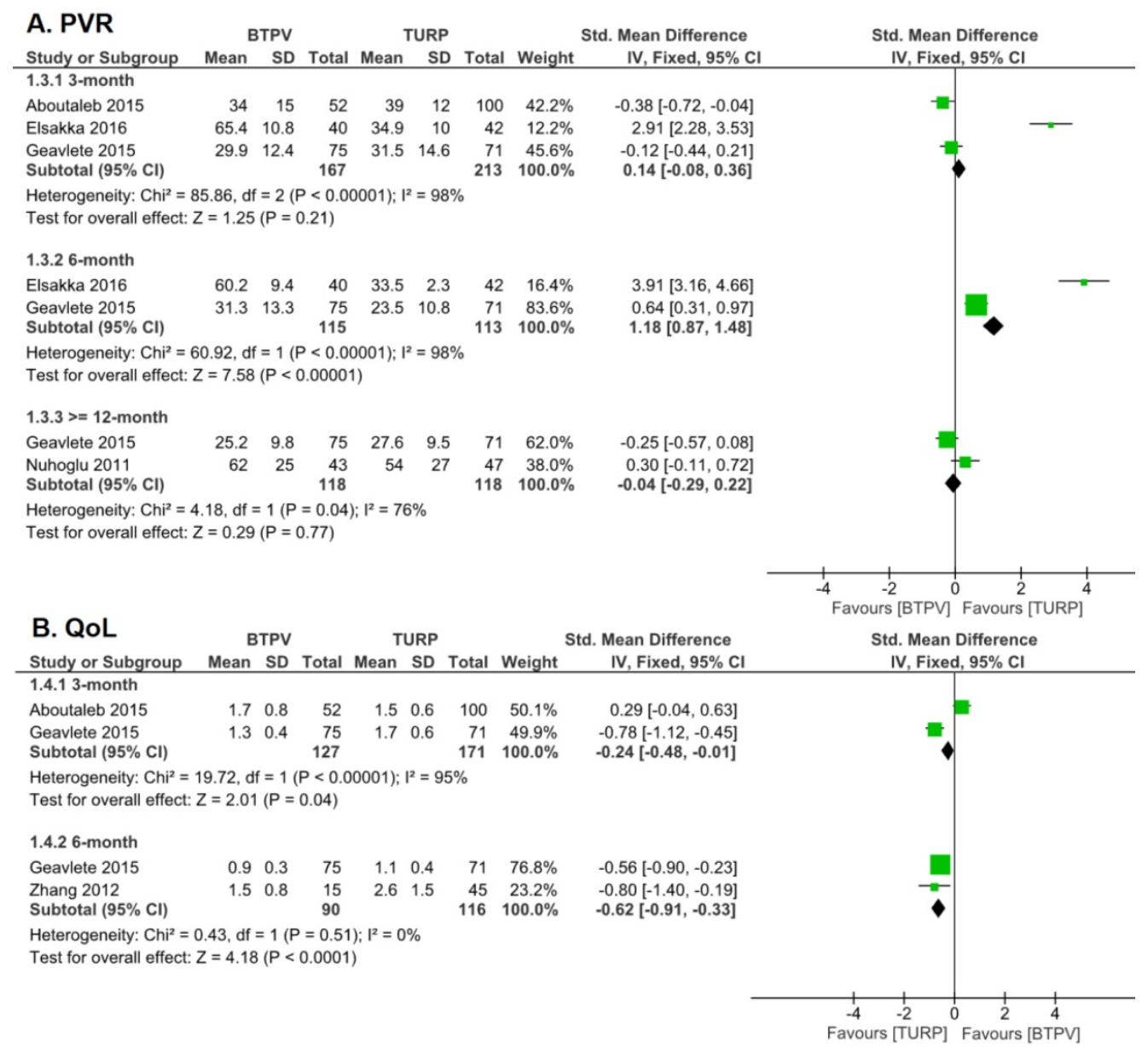

Figure 3. PVR and QoL after treatment. A. PVR; B. QoL

Seven studies including 688 patients compared operative time (Figure 5). Among such studies, three trials reported that the BTPV group had significantly shorter operative time compared to the TURP group, whereas others did not. Generally, the BTPV group had virtually shorter operative time (SMD $-0.15,95 \%$ CI -0.31 to $0.01 ; \mathrm{P}=0.06$ ) compared to the TURP group. Other analyses indicated that BTPV led to significantly lesser hemoglobin drop (SMD -1.09, 95\% CI -1.27 to $-0.91 ; \mathrm{P}<0.00001$ ), shorter catherization time (SMD $-0.96,95 \% \mathrm{CI}-1.12$ to $-0.79 ; \mathrm{P}<0.00001$ ), and shorter hospitalization time (SMD $-0.71,95 \%$ CI -0.89 to -0.53 ; $\mathrm{P}<0.00001$ ).

\section{Subgroup analysis}

The subgroup analysis between BTPV and monopolar TURP (Supplementary Figure S1) derived results similar to those presented above except that the BTPV group had better 3-month Qmax (SMD 0.78, 95\% CI 0.54 to 1.01; $\mathrm{P}<0.00001$ ), worse 3-month PVR (SMD 0.36, 95\% CI 0.06 to $0.65 ; \mathrm{P}=0.02$ ), shorter operative time (SMD $-0.30,95 \%$ CI -0.51 to $-0.08 ; \mathrm{P}<0.00001)$, and fewer Clavien III-IV complications (OR 0.53, 95\% CI 0.30-0.93; P = 0.03).
Moreover, Supplementary Figure S2 indicated that the BTPV group had similar total complications (OR 1.08, 95\% CI 0.40-2.88; $\mathrm{P}=0.88)$, Clavien III-IV complications (OR 1.42, 95\% CI 0.36-5.57, P=0.61) and need for blood transfusion (OR 0.28, 95\% CI 0.04-1.73; $\mathrm{P}=0.17)$ as the bipolar TURP group.

\section{Discussion}

Though TURP has shown promising efficacy as the standard surgical treatment for patients with LUTS/benign prostatic obstruction (BPO), it still possesses limitations. Complications such as bleeding requiring blood transfusion and hematuria, TUR syndrome, and urethral stricture have occurred after TURP. Accordingly, Reich [7] stated that the perioperative morbidity of TURP has dropped over time but has remained noticeable $(11.1 \%)$. Moreover, prolong catheterization time after surgery and frequent retreatment have remain largely unsolved for TURP [22]. Hence, new technologies, such as BTPV, have been introduced. Previous studies compared earlier BTPV systems (i.e., plasma kinetic BTPV) to TURP with results showing no significant difference in short-term efficacy [5, 23]. 

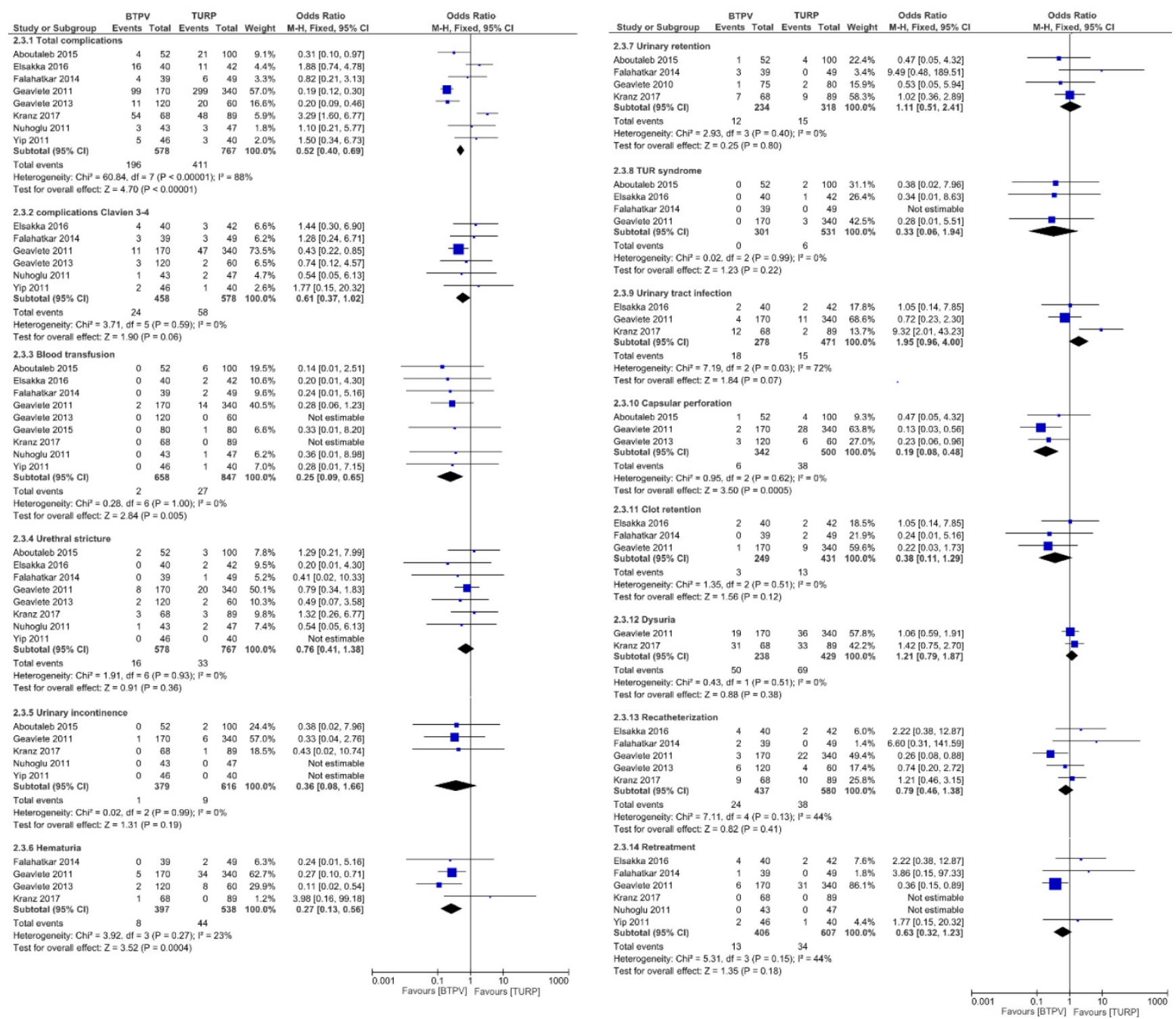

Figure 4. Complications.

A previous study by Wroclawski [10] that focused on comparing "button-type" BTPV and TURP revealed that the two approaches had similar postoperative IPSS (SMD 0.09, 95\% CI -1.56 to 1.73; P $=0.92$ ) and overall complication rates (OR 0.33, 95\% CI 0.08 to $1.31 ; \mathrm{P}=0.12$ ). They also concluded that BTPV and TURP seemed to have similar improvement in symptoms and complications. However, our analysis indicated that TURP had superior 6-month IPSS, 1-, 6- and 12-month Qmax, 6-month PVR, and 3- and 6-month QoL. Moreover, we demonstrated that the BTPV group had a lower overall complication rate. Wroclawski's study [10] lacks sufficient data to assess retreatment or re-catheterization rates between both groups, which the present work evaluates (BTPV vs TURP $=13 / 406$ vs 34/607) and shows that no significant difference existed $(\mathrm{P}=0.18)$. Additionally, the current meta-analysis also expanded the pooled evidence by showing the BTPV group had lower rates of capsular perforation and hematuria, lesser hemoglobin decrease, shorter hospitalization time, and significantly shorter operative time. The superior safety of BTPV was not surprising considering an obvious advantage of laser techniques is the remaining of scar tissue on the incision site that prevents hemorrhage [24]. This could explain the lesser hemoglobin decrease, lesser necessity for blood transfusion, lesser hematuria, and shorter catherization time among the BTPV group. Moreover, less hemorrhage provides better visibility throughout surgery, which could potentially prevent capsular perforation and lead to more efficient, shorter surgeries. Consequently, the fewer complications in the BTPV group could also explain patient's shorter hospitalization time. Generally, the findings 
presented herein showed that both TURP and BTPV significantly improved functional outcomes among with $\mathrm{BPH}$. Furthermore, our findings suggest that BTPV could be an effective alternative to TURP, particularly for selected patients with poor health condition. While BTPV's better safety, shorter catherization and shorter hospitalization may worthwhile, a cost of slightly worse functional outcomes may still be noteworthy. Hence it is crucial to reach a consent with patients about the tradeoffs.

Bipolar TURP has been a widely investigated alternative to monopolar TURP. Notably, three of the included trials deployed bipolar TURP, while the other eight used monopolar TURP. Several studies have proven that bipolar TURP was as equally efficacious as monopolar TURP $[25,26]$ but had even lower perioperative morbidity [27, 28]. Wroclawski also performed sensitivity analysis by excluding studies involving only bipolar TURP and found that outcomes were identical to the combined analysis. Our subgroup analysis wherein comparing BTPV with only monopolar TURP confirmed that the outcomes were generally consistent, although BTPV had significantly shorter operation time and fewer severe complications. Given the limited data available, we also found that BTPV and bipolar TURP had similar total complication, severe complication, and blood transfusion rates.

Compared to the previous study prescribed in this paper, one advantage evident in the current study was the inclusion of a large number of studies and the analysis of more efficacy and safety parameters. Moreover, the previous study combined IPSS data from different follow-up points for analysis, whereas our study unified the reporting standard. Another advantage of the present study was our subgroup analysis. For the first time, BTPV had been compared with only bipolar TURP.

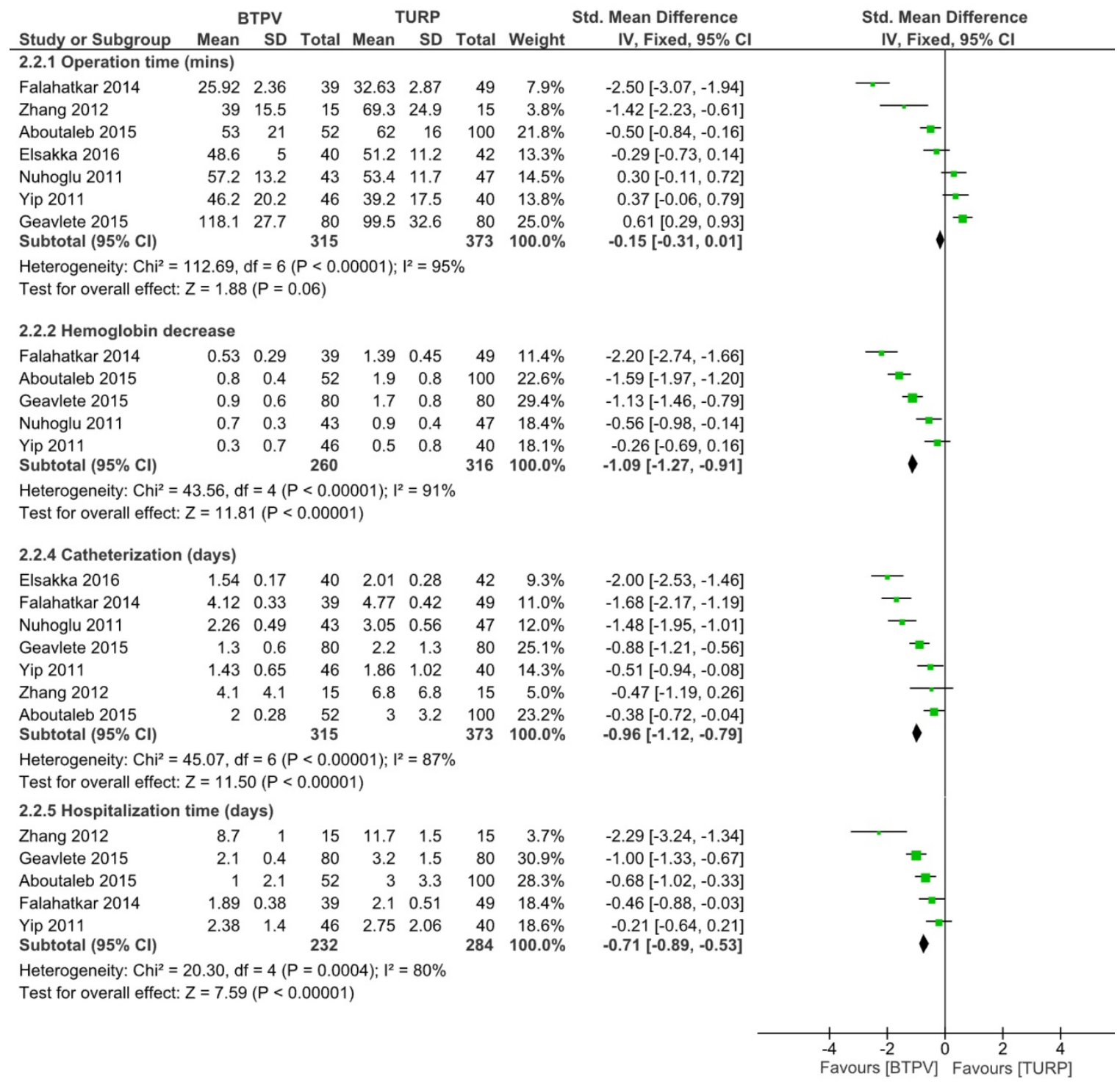

Figure 5. Other intraoperative and postoperative parameters. 
A limitation of the current study was the inclusion of two non-randomized trials. To enhance the reliability of our findings, a separate analysis is conducted by excluding the aforementioned trials. Changes were observed in the analyses of 3-month IPSS, 3-month Qmax, and 3-month PVR, all of which showed significant differences, which contradicted the findings of the previously study. However, outcomes related to complications and longer follow-up during efficacy analysis remained the same after exclusion. Therefore, every study was included in the meta-analysis in order to obtain a comprehensive review of all related investigations.

Although most studies enrolled patients with a mean prostate volume of $30-80 \mathrm{~mL}$, one study had a mean prostate volume of $124.3 \mathrm{~mL}$. Accordingly, the latest EAU guideline recommends that TURP be primarily considered for a prostate volume of 30-80 $\mathrm{mL}$ based on expert opinion [4]. Nevertheless, no studies on the optimal cut-off value actually exist as stated in the guideline.

Limitations should be noted before interpreting our findings. The follow-up was mostly no more than 12 months, while the longest follow-up was 18 months. Hence, our outcomes could only compare short-term efficacy and safety between BTPV and TURP. Accordingly, limited follow-up might underestimate complications that may occur at a later time, which implore more high-quality trials with longer follow-up durations. Furthermore, the reporting of complications could be biased given that follow-up duration in the studies was not uniform. Moreover, we were not able to assess voiding IPSS and storage IPSS, which should be considered in future trials.

\section{Conclusion}

The current study suggested both TURP and BTPV could significantly improve IPPS, Qmax, PVR, and QoL among patients with LUTS/BPO. Further analysis based on previous studies revealed that TURP seemed to have generally slightly better short-term efficacy, whereas BTPV had better safety and tolerability. However, subgroup analysis found that bipolar TURP and BTPV had similar safety.

\section{Abbreviations}

BTPV: Button-type bipolar plasma vaporization; TURP: Transurethral resection of prostate; BPH: Benign prostatic hyperplasia; LUTS: Lower urinary tract symptoms; BOO: Bladder outlet obstruction; BPE: Benign prostatic enlargement; IPSS: International Prostate Symptom Score; Qmax: Maximum flow rate; PVR: Postvoiding residual; QoL:
Quality of Life; CI: Confidence interval; SMD: Standard mean difference; OR: Odds ratio.

\section{Supplementary Material}

Supplementary figures and tables. http://www.medsci.org/v16p1564s1.pdf

\section{Acknowledgement}

This research is supported by National Natural Science Foundation of China (Grant No. 81702536, 81370855, 81770756), Programs from Science and Technology Department of Sichuan Province (Grant No. 2018HH0153 and 2017HH0063), National Key Research and Development Program of China (Grant No. SQ2017YFSF090096) and Grant of 1.3.5 Project for Disciplines of Excellence (ZYGD18011).

\section{Competing Interests}

The authors have declared that no competing interest exists.

\section{References}

1. Chapple C. \& Abrams P. E. Société Internationale d'Urologie (SIU), Lower Urinary Tract Symptoms (LUTS): An International Consultation on Male LUTS. 2013.

2. Abrams P, Cardozo L, Fall M, Griffiths D, Rosier P, Ulmsten U, et al. The standardisation of terminology in lower urinary tract function: report from the standardisation sub-committee of the International Continence Society. Urology. 2003; 61: 37-49.

3. Kupelian V, Wei JT, O'Leary MP, Kusek JW, Litman HJ, Link CL, et al. Prevalence of lower urinary tract symptoms and effect on quality of life in a racially and ethnically diverse random sample: the Boston Area Community Health (BACH) Survey. Archives of internal medicine. 2006; 166: 2381-7.

4. EAU Guidelines. Edn. presented at the EAU Annual Congress Barcelona 2019. ISBN 978-94-92671-04-2.

5. Ahyai SA, Gilling P, Kaplan SA, Kuntz RM, Madersbacher S, Montorsi F, et al. Meta-analysis of functional outcomes and complications following transurethral procedures for lower urinary tract symptoms resulting from benign prostatic enlargement. European urology. 2010; 58: 384-97.

6. Madersbacher S, Marberger M. Is transurethral resection of the prostate still justified? BJU international. 1999; 83: 227-37.

7. Reich O, Gratzke C, Bachmann A, Seitz M, Schlenker B, Hermanek P, et al. Morbidity, mortality and early outcome of transurethral resection of the prostate: a prospective multicenter evaluation of 10,654 patients. The Journal of urology. 2008; 180: 246-9.

8. Bucuras V, Bardan R. Bipolar vaporization of the prostate: is it ready for the primetime? Therapeutic advances in urology. 2011; 3: 257-61.

9. Reich O, Schlenker B, Gratzke C, Tilki D, Riecken M, Stief C, et al. Plasma vaporisation of the prostate: initial clinical results. European urology. 2010; 57: 693-7.

10. Wroclawski ML, Carneiro A, Amarante RD, Oliveira CE, Shimanoe V, Bianco BA, et al. 'Button type' bipolar plasma vaporisation of the prostate compared with standard transurethral resection: a systematic review and meta-analysis of short-term outcome studies. BJU international. 2016; 117: 662-8.

11. Aboutaleb H. Efficacy of bipolar "button" plasma vaporization of the prostate for benign prostatic obstruction, compared to the standard technique. Urology annals. 2015; 7: 442-7.

12. Elsakka AM, Eltatawy HH, Almekaty KH, Ramadan AR, Gameel TA, Farahat Y. A prospective randomised controlled study comparing bipolar plasma vaporisation of the prostate to monopolar transurethral resection of the prostate. Arab journal of urology. 2016; 14: 280-6.

13. Falahatkar S, Mokhtari G, Moghaddam KG, Asadollahzade A, Farzan A, Shahab E, et al. Bipolar transurethral vaporization: a superior procedure in benign prostatic hyperplasia: a prospective randomized comparison with bipolar TURP. International braz j urol : official journal of the Brazilian Society of Urology. 2014; 40: 346-55.

14. Geavlete B, Georgescu D, Multescu R, Stanescu F, Jecu M, Geavlete P. Bipolar plasma vaporization vs monopolar and bipolar TURP-A prospective, randomized, long-term comparison. Urology. 2011; 78: 930-5.

15. Geavlete B, Multescu R, Dragutescu M, Jecu M, Georgescu D, Geavlete P. Transurethral resection (TUR) in saline plasma vaporization of the prostate vs 
standard TUR of the prostate: 'the better choice' in benign prostatic hyperplasia? BJU international. 2010; 106: 1695-9.

16. Geavlete B, Stanescu F, Moldoveanu C, Geavlete P. Continuous vs conventional bipolar plasma vaporisation of the prostate and standard monopolar resection: a prospective, randomised comparison of a new technological advance. BJU international. 2014; 113: 288-95.

17. Nuhoglu B, Balci MB, Aydin M, Hazar I, Onuk O, Tas T, et al. The role of bipolar transurethral vaporization in the management of benign prostatic hyperplasia. Urologia internationalis. 2011; 87: 400-4.

18. Kranzbuhler B, Gross O, Fankhauser CD, Wettstein MS, Grossmann NC, Hefermehl LJ, et al. Prostate volume reduction following pure transurethral bipolar plasma vaporization and conventional transurethral resection of the prostate: a prospective investigation using transrectal 3D ultrasound volumetry. World journal of urology. 2017; 35: 429-35.

19. Yip SK, Chan $\mathrm{NH}$, Chiu P, Lee KW, Ng CF. A randomized controlled trial comparing the efficacy of hybrid bipolar transurethral vaporization and resection of the prostate with bipolar transurethral resection of the prostate. Journal of endourology. 2011; 25: 1889-94.

20. Zhang SY, Hu H, Zhang XP, Wang D, Xu KX, Na YQ, et al. Efficacy and safety of bipolar plasma vaporization of the prostate with "button-type" electrode compared with transurethral resection of prostate for benign prostatic hyperplasia. Chinese medical journal. 2012; 125: 3811-4.

21. Geavlete B, Bulai C, Ene C, Checherita I, Geavlete P. Bipolar vaporization, resection, and enucleation versus open prostatectomy: optimal treatment alternatives in large prostate cases? Journal of endourology. 2015; 29: 323-31.

22. Madersbacher S, Lackner J, Brossner C, Rohlich M, Stancik I, Willinger M, et al. Reoperation, myocardial infarction and mortality after transurethral and open prostatectomy: a nation-wide, long-term analysis of 23,123 cases. European urology. 2005; 47: 499-504.

23. Robert G, de la Taille A, Herrmann T. Bipolar plasma vaporization of the prostate: ready to replace GreenLight? A systematic review of randomized control trials. World journal of urology. 2015; 33: 549-54.

24. Torres Castellanos L, Moreno Bencardino MC, Bravo-Balado A, Garcia Mayorga CA, Vargas Manrique I, Fernandez N. Evaluation of the Efficacy and Safety of Laser versus Cold Knife Urethrotomy in the Management of Patients with Urethral Strictures: A Systematic Review and Meta-Analysis of Randomized Clinical Trials. Urologia internationalis. 2017; 99: 453-9.

25. Mamoulakis C, Ubbink DT, de la Rosette JJ. Bipolar versus monopolar transurethral resection of the prostate: a systematic review and meta-analysis of randomized controlled trials. European urology. 2009; 56: 798-809.

26. Omar MI, Lam TB, Alexander CE, Graham J, Mamoulakis C, Imamura M, et al. Systematic review and meta-analysis of the clinical effectiveness of bipolar compared with monopolar transurethral resection of the prostate (TURP). BJU international. 2014; 113: 24-35.

27. Inzunza G, Rada G, Majerson A. Bipolar or monopolar transurethral resection for benign prostatic hyperplasia? Medwave. 2018; 18: e7134.

28. Stucki P, Marini L, Mattei A, Xafis K, Boldini M, Danuser H. Bipolar versus monopolar transurethral resection of the prostate: a prospective randomized trial focusing on bleeding complications. The Journal of urology. 2015; 193: 1371-5. 